\title{
lin-31, a Caenorhabditis elegans HNF-3/ fork head transcription factor homolog, specifies three alternative cell fates in vulval development
}

\author{
Leilani M. Miller, Maria E. Gallegos, Barbara Anne Morisseau, and Stuart K. Kim ${ }^{1}$ \\ Department of Developmental Biology, Stanford University Medical Center, Stanford, California 94305 USA.
}

\begin{abstract}
Cell-cell signaling controls the specification of vulval cell fates in Caenorhabditis elegans. Although previous studies have identified genes that function at early steps in the signaling pathway, the late steps are not well understood. Here, we begin to characterize those late events by showing that the lin-31 gene acts near the end of the vulval signaling pathway. We show that lin-31 acts downstream of the ras homolog let-60 and that lin-31 encodes a member of the HNF-3/fork head family of DNA-binding transcription factors. lin-31 regulates how vulval precursor cells choose their fate; in lin-31 mutants, these cells do not properly choose which fate to express and therefore adopt any one of the three possible vulval cell fates in a deregulated fashion. This interesting mutant phenotype suggests mechanisms for how vulval cell fates become determined.
\end{abstract}

[Key Words: Caenorhabditis elegans; lin-31; HNF-3; fork head; vulval development]

Received February 2, 1993; revised version accepted March 19, 1993.

Cell-cell signaling plays an important role in controlling cellular proliferation, in specifying cell fates, and in regulating the basic developmental processes of induction and pattern formation. In the nematode Caenorhabditis elegans, cell-cell signaling has been dissected using genetic studies to identify many genes within a given signaling pathway and molecular studies to show how these signaling genes function (Lambie and Kimble 1991). One of the best studied examples of cell signaling in C. elegans occurs during the development of the hermaphrodite vulva. A set of six initially equivalent vulval precursor cells (P3.p-P8.p, referred to as Pn.p cells in this paper) adopt one of three potential cell fates $\left(1^{\circ}, 2^{\circ}\right.$, or $\left.3^{\circ}\right)$ in response to extracellular signals (Fig. 1 ; for review, see Horvitz and Sternberg 1991|. The major inductive signal comes from the anchor cell in the somatic gonad. This cell induces the formation of a vulva, because no vulva is formed if the anchor cell is ablated (Kimble 1981). The anchor cell causes the nearest Pn.p cell (P6.p) to adopt a $1^{\circ}$ cell fate and induces Pn.p cells at an intermediate distance (P5.p and P7.p) to adopt $2^{\circ}$ cell fates. Pn.p cells that are far from the anchor cell (P3.p, P4.p, and P8.p) adopt the uninduced $3^{\circ}$ fate (Sternberg and Horvitz 1986). The cells generated by the $1^{\circ}$ and $2^{\circ}$ cell lineages form the vulva, and the cells generated by the $3^{\circ}$ cell lineages contribute to the epidermis (see Fig. 1). In addition to the

\footnotetext{
${ }^{1}$ Corresponding author.
}

anchor cell signal, a lateral signal is produced by the Pn.p cells themselves, such that a cell expressing a $1^{\circ}$ cell fate prevents its neighbors from adopting the same fate (Sternberg 1988). Finally, Pn.p cell fates are influenced by the syncytial epidermis, because this tissue limits the number of Pn.p cells that express induced cell fates (Herman and Hedgecock 1990). Thus, initially equivalent vulval precursor cells integrate input from several signaling pathways to choose between alternative vulval cell fates.

Genetic studies have identified at least 17 genes that are required for the proper functioning of these vulval signaling pathways (Ferguson and Horvitz 1985; Beitel et al. 1990; Han et al. 1990; Clark et al. 1992). Mutations in these genes result in signaling defects such that certain Pn.p cells adopt inappropriate vulval cell fates. These genes can be separated into three phenotypic classes. Loss-of-function mutations in genes of the first class (Iin2 , lin-3, lin-7, lin-10, let-23, let-60, and sem-5) result in a vulvaless phenotype. In vulvaless mutants, all of the Pn.p cells express the $3^{\circ}$ cell fate, resulting in animals that have no vulva and cannot lay eggs. Loss-of-function mutations in genes of the second class (lin-1, lin-8, lin-9, lin-13, lin-15, lin-35, lin-36, lin-37, and lin-38) contribute to a multivulva phenotype. In these multivulva animals, all of the Pn.p cells express induced (either $1^{\circ}$ or $\left.2^{\circ}\right)$ cell fates, resulting in the generation of extra vulval cells and the subsequent formation of ventral protrusions. Loss-of-function mutations in lin-31, the single 


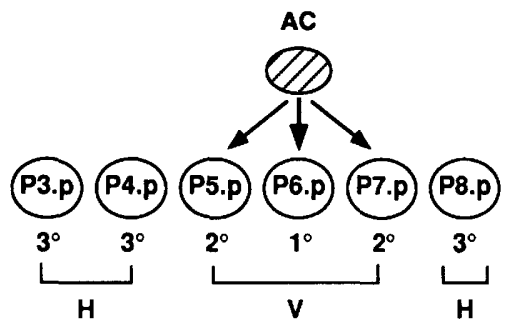

Figure 1. Specification of vulval precursor cell fates. A model for vulval induction in wild-type hermaphrodites. The six vulval precursor cells (P3.p-P8.p) adopt one of three cell fates $\left(1^{\circ}\right.$, $2^{\circ}$, or $\left.3^{\circ}\right)$ in response to an inductive signal from the gonadal anchor cell $(\mathrm{AC})$. The $1^{\circ}$ and $2^{\circ}$ cell lineages form the vulva (V), and the $3^{\circ}$ cell lineages contribute to the hypodermis $(\mathrm{H})$. For the sake of simplicity (see text), the lateral and hypodermal signals are not shown here.

member of the third class, result in a range of phenotypes characteristic of both the vulvaless and multivulva classes. For example, in a lin-31 mutant strain, some animals cannot lay eggs, others have ventral protrusions, and most of the remaining animals exhibit both phenotypes (Ferguson and Horvitz 1985; Kim and Horvitz 1990).

A pathway for anchor cell signaling has been proposed based on the similarity of four genes in the vulvaless class to genes in mammalian signaling pathways (Horvitz and Sternberg 1991). In this model, the signaling pathway begins when the anchor cell expresses an inductive signal, which is encoded by the lin-3 gene and is similar in structure to epidermal growth factor (Hill and Sternberg 1992). The receptor for the anchor cell signal is the let-23 gene product, which is homologous to tyrosine kinases of the epidermal growth factor receptor family (Aroian et al. 1990). Interaction between the lin-3 ligand and the let-23 receptor leads to the activation of two signal transduction molecules, encoded by the sem. 5 and let- 60 genes. The sem- 5 gene product has an $\mathrm{SH} 2$ domain and therefore may physically interact with phosphotyrosine residues generated by an activated let-23 receptor (Clark et al. 1992). The let-60 gene product is the homolog of the ras signal transduction molecule and presumably functions in the transduction of a signal from an activated let-23 receptor (Han and Sternberg 1990).

In addition to identifying genes with familiar biochemical functions, genetic analyses have identified other genes required for vulval cell signaling that may have novel functions. For example, molecular analysis of lin-10 shows that the lin-10 gene product is not homologous to previously identified signaling molecules (Kim and Horvitz 1990), and genes such as this will likely serve as pioneers for the identification of new steps in signaling pathways.

Genetic analyses of vulvaless and multivulva genes suggest that all of those genes act upstream of let-60, with the exception of lin-1 (Han et al. 1990). Specifically, constitutive mutations in let-60 can bypass the requirement for any of the other six vulvaless genes for the expression of induced cell fates (Han et al. 1990; S. Kim, J. Simske, R. Hoskins, unpubl.; S. Clark, pers. comm.), whereas loss-of-function let-60 mutations prevent induction caused by multivulva mutations, with the exception of lin-1 mutations (Han et al. 1990). These results are intriguing, as ras homologs such as let- 60 should act early in signal transduction pathways because their gene products are usually found associated with the plasma membrane (Kim et al. 1990). Thus, an obvious class of genes that is under-represented in the current vulval signal transduction pathway is the class whose members act after let-60. This class includes genes that are involved in transducing the signal from the plasma membrane to the nucleus and others that direct lineagespecific gene expression in the nucleus.

In this report we present evidence from cell ablation and genetic epistasis experiments that the lin-31 gene acts after let-60 ras, at a late step in the anchor cell signaling pathway. We have cloned the lin-31 gene and find that the 1 in-31 predicted protein is a member of the hepatocyte nuclear factor 3 (HNF-3)/fork head transcription factor family and is thus likely to determine cell fates by acting as a transcriptional regulator of vulval lineage gene expression. In addition, we have analyzed Pn.p cell lineage defects in lin-31 mutants and have found that cell fates are deregulated, such that each of the six Pn.p cells can express any of the three vulval cell fates. This deregulated mutant phenotype suggests that lin-31 does not directly control the transcription of terminal differentiation genes but controls the expression of regulatory circuits that specify vulval cell fates.

\section{Results}

\section{Deregulated vulval cell lineages in lin-31 mutants}

Mutants that are homozygous for any of the $17 \operatorname{lin}-31$ alleles exhibit a range of vulval defects: Some animals have a defective vulva and are unable to lay eggs, some have ventral protrusions similar to multivulva mutants, and some display both phenotypes (Ferguson and Horvitz 1985; Kim and Horvitz 1990). To determine the cellular basis for these morphological abnormalities, we analyzed the patterns of Pn.p cell lineages in lin-31 mutants by observing animals using Nomarski optics. As discussed below, the two lin-31 mutations used in this study (n301 and n1053) likely result in the elimination of lin-31 activity. Our cell lineage analysis revealed three separate defects in the developmental behavior of Pn.p cells: deregulated expression of vulval precursor cell fates, defective lateral signaling, and occasional extra division of Pn.p cells. This report focuses on the first defect. Although vulval precursor cells in wild-type animals express their fates in a precise pattern, the vulval precursor cells in lin-31 mutant animals express their fates in a deregulated fashion. We observed that a particular vulval precursor cell (e.g., P5.p) could express different fates in different mutant animals. Upon determining the Pn.p cell lineages in 10 lin-31 mutant animals, we 
found that each of the six vulval precursor cells had expressed each of the three possible cell fates $\left(1^{\circ}, 2^{\circ}\right.$, or $\left.3^{\circ}\right)$ in one animal or another (Fig. 2A). Moreover, we often observed opposite cell fate transformations in the same lin-31 mutant animal. For example, in one particular animal, we observed that P7.p had undergone a $2^{\circ}$ to $3^{\circ}$ cell fate transformation, whereas P8.p had simultaneously undergone a $3^{\circ}$ to $2^{\circ}$ cell fate transformation (Fig. 2A, animal 1). Of 10 animals examined, 7 exhibited opposite cell fate transformations, in which a Pn.p cell distal to the anchor cell expressed an induced cell fate $\left(1^{\circ}\right.$ or $\left.2^{\circ}\right)$ and a proximal Pn.p cell simultaneously expressed an uninduced $\left(3^{\circ}\right)$ cell fate (Fig. 2A, animals $1-4$ and 6-8). These opposite cell fate transformations indicate that in lin-31 mutants, the choice of cell fate is no longer strictly dependent on proximity to the anchor cell. A currently unexplained observation is the bias regarding the choice of cell fates expressed by different Pn.p cells in lin-31 mutants. For example, although P6.p is able to express any vulval cell fate in a lin-31 mutant, it most frequently expresses the $1^{\circ}$ cell fate (see Fig. 2A).

We used four criteria to verify that the cells generated by the inappropriate Pn.p cell lineages in lin-31 mutants were vulval cells (generated by $1^{\circ}$ or $2^{\circ}$ cell lineages) or epidermal cells (generated by the $3^{\circ}$ cell lineage), rather than some other cell type. First, nearly all of the Pn.p cells (57 of 66) expressed a cell division pattern typical of normal $1^{\circ}, 2^{\circ}$, or $3^{\circ}$ cell lineages (Fig. 2A). Second, the descendants of the vulval precursor cells in lin-31 mutants were morphologically similar to those generated by the normal $1^{\circ}, 2^{\circ}$, or $3^{\circ}$ cell lineages. For example, during the fourth larval stage, cells generated by the $1^{\circ}$ and $2^{\circ}$ cell lineage migrate basally, extend cellular processes toward each other, fuse, and eventually form six concentric cellular rings (J. White, pers. comm.). In lin-31 mutants, these cellular rings were plainly visible when $P 3 . p$, P4.p, or P8.p inappropriately expressed either $1^{\circ}$ or $2^{\circ}$ cell lineages (Fig. 3B). Third, we used the lectin concanavalin A (Con A) as a molecular marker to show that lin-31 mutants have extra vulval cells. In wild-type animals, Con A specifically stains cells generated by the $1^{\circ}$ and $2^{\circ}$ vulval cell lineages (Link et al. 1988; G. Freyd, pers. comm.; Fig. 3E). Using Con A that had been conjugated to fluorescein isothiocyanate (FITC) to allow visualiza-

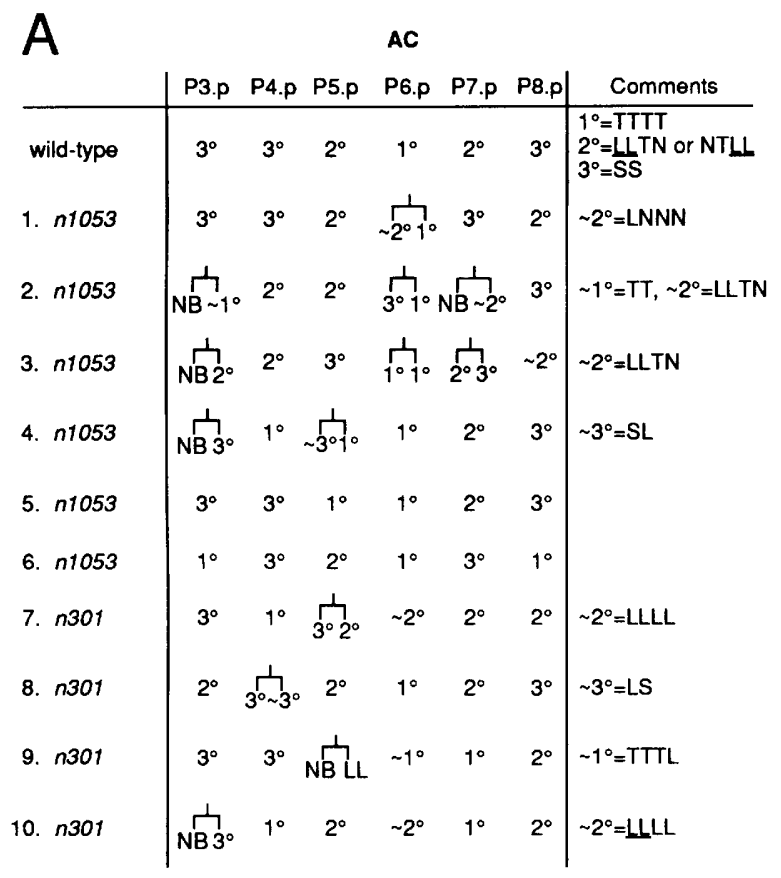

podermal syncytium (S). In the lin-31 mutant strains (n10 identical to one of the three normal fates $\left(1^{\circ}, 2^{\circ}\right.$ or $\left.3^{\circ}\right)$. Thus, the one vulval precursor cell expresses the fate normally expressed by another vulval precursor cell. Other cells expressed hybrid lineages, indicated by $\sim 1^{\circ}, \sim 2^{\circ}$, and $\sim 3^{\circ}$; the exact patterns of cell division for these aberrant lineages are described under Comments. [(L) Lateral division without attachment to the cuticle]. Inappropriate L2 divisions are represented by lineage brackets. For the purposes of this paper, we considered vulval precursor cells to be equivalent whether or not they were derived from a division in the second larval stage. (NB) A neuroblast-like fate. $(B)$ Effect of Z1/Z4 ablation on the fates of vulval precursor cells in lin-31 mutants. Z1 and Z4 are the two potential precursors of the anchor cell, and no anchor cell is formed when they are ablated. $\mathrm{Zl}$ and $\mathrm{Z} 4$ were ablated using a laser microbeam in lin-31(n1053) animals during the L1 larval stage. The cell lineages of Pn.p cells were followed during the L3 larval stage. Induced cell fates were clearly observed in lin-31 animals lacking an anchor cell. Anchor cell ablation, however, reduced the frequency of Pn.p cell induction seen in lin-31 mutants. One possibility is that the Pn.p cells were mildly damaged by the laser treatment and thus could not always express induced fates. A second possibility is that other genes may act at the same step as lin-31 and that these genes allow the anchor cell signal to partially bypass a lin-31 defect. (AC) Anchor cell; (O) oblique division (in SOTT). 
N2

Figure 3. $\quad$ lin-31 vulval phenotypes. $(A)$ Wildtype animal during the L4 larval stage, viewed by Nomarski optics microscopy. The cellular descendants of P5.p, P6.p, and P7.p have begun to invaginate to form the vulva. The location of the descendants of each Pn.p cell is shown by a line (the double line marks the location of the P6.p descendants). Vulval cells (V) and hypodermal cells $(\mathrm{H})$ are marked. For the animals shown here and in Fig. 4, ventral is down and anterior is to the left. (B) lin-31(n1053) animal during the L4 larval stage, viewed by Nomarski optics microscopy. In this animal, a distal cell (P4.p) has generated vulval cells as a result of the expression of an induced cell fate $\left(1^{\circ}\right.$ or $\left.2^{\circ}\right)$, whereas a more proximal cell (P5.p) has generated hypodermal cells as a result of the expression of the ground state $\left(3^{\circ}\right)$ cell fate. Bar, indicating scale for A and B, $10 \mu \mathrm{m}$. $(C-F)$ Adult animals were stained with FITC-Con A and viewed either by Nomarski $(C, D)$ or by fluorescence microscopy $(E, F)$. In wild-type animals, the vulva is seen as a ventral opening $(C)$ or as a region that stains with FITC-Con A $(E)$. In lin-31|n1053) animals, extra vulval cells are produced that result in ventral protrusions $(D)$ or as regions that stain with FITC-Con A $(F)$. Arrows indicate position of the vulva; arrowheads indicate positions of extra vulval cells. Bar, for C-F, $25 \mu \mathrm{m}$.
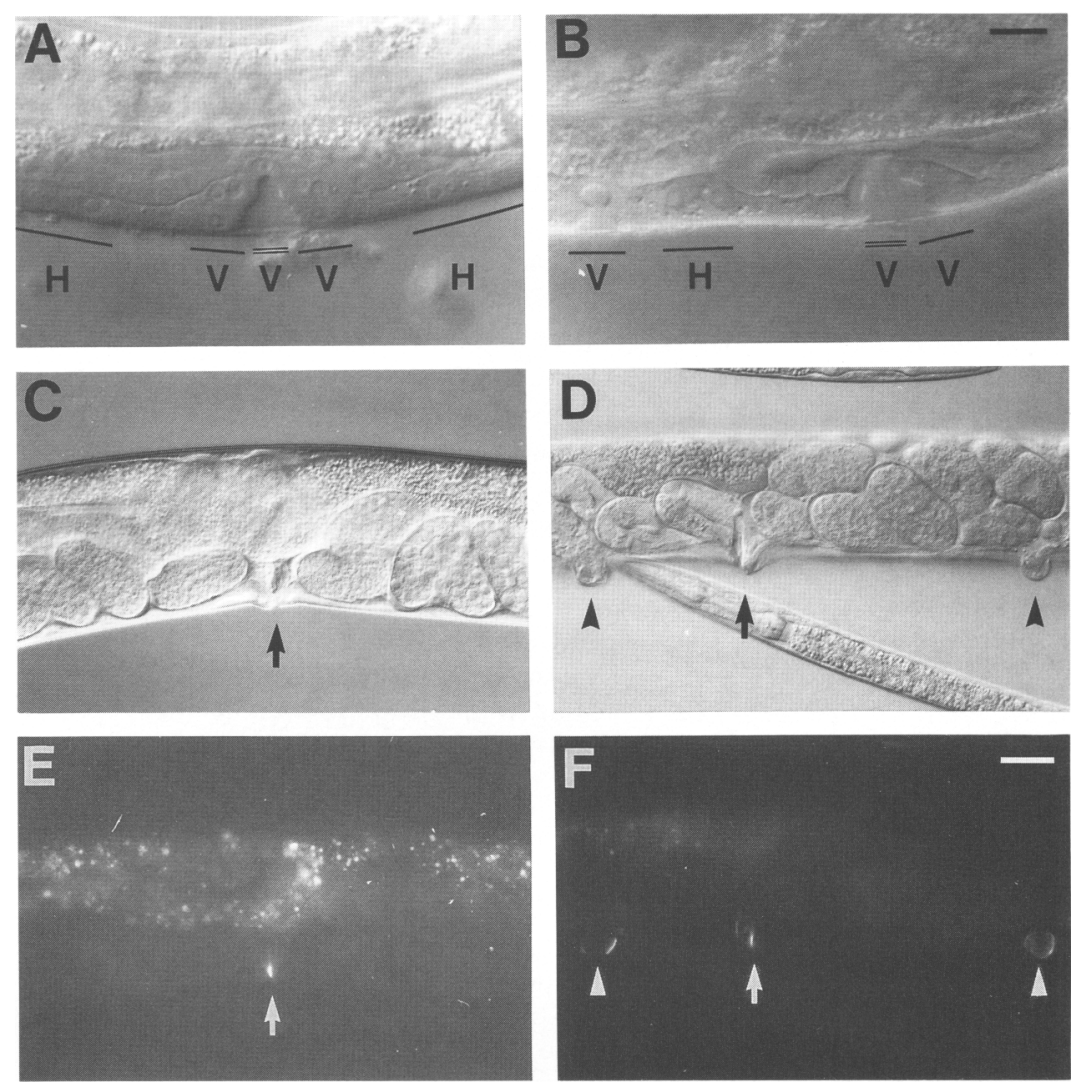

tion by fluorescence microscopy, we showed that P3.p, P4.p, and P8.p could generate cells that stain with FITCCon A in lin-31 mutants (Fig. 3F). Finally, in certain genetic backgrounds, lin-31 mutations can result in the transformation of epidermal tissue into a functional vulva. Specifically, vulvaless mutants cannot lay eggs because all of the Pn.p cells express $3^{\circ}$ cell lineages and generate only epidermal tissue. Animals that are mutant in both a vulvaless locus and the lin-31 gene, however, can lay eggs, showing that the lin-31 mutation has caused functional vulval tissue to be formed instead of epidermal tissue (Table 2, below). Thus, on the basis of the pattern of cell division, cellular morphology, staining with a molecular marker, and the generation of functional vulval cells, Pn.p cells in lin-31 mutant animals express one of the three potential vulval fates $\left(1^{\circ}, 2^{\circ}\right.$ or $\left.3^{\circ}\right)$, although they adopt these fates in a deregulated manner.

In addition to deregulated cell fates, a second aspect of the lin-31 mutant phenotype is that vulval cell fates are no longer controlled by the lateral signaling pathway. In wild-type animals, only one cell (P6.p) is ever seen to adopt the $1^{\circ}$ cell fate, because this cell sends out a lateral signal that prevents its neighbors from also adopting the $1^{\circ}$ cell fate. In lin-31 mutants, however, two adjacent Pn.p cells have been observed to adopt $1^{\circ}$ cell fates in several cases (Fig. 2A, animals $3-5$ ). This result suggests that the lateral signaling pathway is defective, either because Pn.p cells can no longer send a lateral signal or because they can no longer respond to it. A third defect observed in lin-31 mutant hermaphrodites is the division of some Pn.p cells during the L2 larval stage, at a time when these cells are normally quiescent. These divisions produce either an extra vulval precursor cell or an extra cell with a neuroblast fate, similar to the normal fate of the Pn.a cells (the sisters of the vulval precursor cells). These three vulval defects are the only obvious phenotypes observed in lin-31 mutant hermaphrodites, suggesting that the function of lin-31 in hermaphrodites may be specific for vulval cell fate determination.

Four lines of evidence indicate that most of our lin-31 alleles either eliminate or severely reduce lin-31 gene activity. First, putative null alleles are the most common type of lin-31 mutation and display the most severe mutant phenotype. Of the 17 alleles that have been analyzed, 16 exhibit highly penetrant vulval lineage defects (Table 1). Second, for the two alleles tested (n301 and n1053|, lin-31/lin-31 and lin-31/deficiency animals display the same phenotype (Materials and methods; Greenwald and Horvitz 1980). This result indicates that these two alleles likely result in the elimination of lin-31 gene activity because a reduction by half in the mutant 
Table 1. lin-31 Alleles

\begin{tabular}{llrc}
\hline Allele & Mutagen $^{\text {a }}$ & N & Percentage mutant $^{\text {b }}$ \\
\hline ga9 & mutator & 1294 & 98 \\
n1053 & EMS & 2529 & 96 \\
n1049 & EMS & 1167 & 96 \\
n1048 & EMS & 510 & 96 \\
n1290 & mutator & 1684 & 95 \\
e1750 & EMS & 484 & 95 \\
n428 & EMS & 1011 & 95 \\
n429 & EMS & 1162 & 95 \\
ga10 & EMS & 909 & 94 \\
n1050 & EMS & 1521 & 94 \\
n376 & EMS & 1149 & 93 \\
n301 & EMS & 1098 & 91 \\
n762 & EMS & 525 & 91 \\
n1282 & mutator & 1195 & 89 \\
ga37 & mutator & 906 & 87 \\
n435 & EMS & 989 & 82 \\
n1291 & mutator & 1381 & 63 \\
\hline
\end{tabular}

${ }^{a}$ Mutator alleles were isolated in a strain with high transposon activity (Kim and Horvitz 1990). (EMS) Ethylmethane sulfonate. bThe percentage of animals that were either multivulva, vulvaless, egg-laying defective, had ruptured at the vulva, or any combination of the above.

gene dose does not increase the severity of the mutant phenotype. Third, three alleles (n1282, n1291, and ga37) are insertion mutations and one allele (n376) is a deletion within the lin-31 locus (see below). Fourth, the lin31 (ga37) mutation prevents the accumulation of the lin31 transcript (see below). These results indicate that the cell lineage defects observed in these mutants likely represent the lin-31 null phenotype.

\section{lin-31 acts at a late step in the anchor cell signaling pathway}

To ascertain at which step lin-31 acts in the anchor cell signaling pathway, we determined whether the expression of $1^{\circ}$ and $2^{\circ}$ cell fates in lin-31 mutants is dependent on other components of the pathway. If lin-31 were to act early in the pathway, one would expect that the expression of induced cell fates in lin-31 mutants would be dependent on the activity of downstream components of the anchor cell signaling pathway. One component of the pathway is the anchor cell itself, because this cell is the source of the inductive signal. We physically removed the anchor cell inductive signal by using laser microsurgery to ablate the precursors of the anchor cell. In wild-type animals, this operation causes all Pn.p cells to express the $3^{\circ}$ cell fate (Kimble 1981; Sternberg and Horvitz 1986). When the anchor cell precursors were ablated in lin-31 mutants, however, we observed that Pn.p cells could still express $1^{\circ}$ and $2^{\circ}$ cell fates; 24 of 82 Pn.p cells expressed an induced fate after laser ablation (Fig. 2B; data not shown). The pattern of cell divisions and the morphology of the cells generated by Pn.p cells in lin-31 mutants lacking an anchor cell was typical for vulval precursor cells. Therefore, $1^{\circ}$ and $2^{\circ}$ cell fates can be ex- pressed in the absence of an inductive signal from the anchor cell in lin-31 mutants.

We then analyzed animals in which the activities of other components of the anchor cell signaling pathway were defective as a result of mutations in any one of five genes (lin-2, lin-7, lin-10, let-23, and let-60). Each of these genes has a vulvaless mutant phenotype, in which all Pn.p cells adopt $3^{\circ}$ cell fates (Ferguson and Horvitz 1985; Beitel et al. 1990; Han et al. 1990; Kim and Horvitz 1990). Animals that are doubly mutant for lin-31 and any one of the five vulvaless genes mentioned above display a phenotype similar to the lin-31 mutant phenotype (Table 2). Specifically, in all of these doubly mutant strains, most animals (72-95\%) display a multivulva phenotype, as a result of the inappropriate expression of $1^{\circ}$ or $2^{\circ}$ cell

Table 2. lin-31 is epistatic to other vulval determination genes

\begin{tabular}{lccc}
\hline Genotype & N & $\begin{array}{c}\text { Percentage } \\
\text { multivulva }\end{array}$ & Vulva $^{\mathrm{c}}$ \\
\hline lin-31 & 189 & 77 & + \\
lin-31 at $15^{\circ}$ & 138 & 93 & + \\
lin-2 & 176 & 0 & - \\
lin-7 & 196 & 0 & - \\
lin-10 & 240 & 0 & - \\
let-23 at $15^{\circ}$ & 250 & 0 & - \\
let-60|dn) $/+^{\mathrm{d}}$ & 200 & 0 & - \\
lin-31; lin-2 & 180 & 95 & + \\
lin-31; lin-7 & 243 & 72 & + \\
lin-10; lin-31 & 191 & 85 & + \\
lin-31; let-60/+ & 186 & 80 & + \\
lin-31; let-23 at $15^{\circ}$ & 113 & 80 & + \\
\hline
\end{tabular}

aAlleles used: Null, or nearly null, alleles were used for the following genes: lin-31(n1053), lin-2(e1309), lin-7(e1413), and lin-10(n1390) (Kim and Horvitz 1990; R. Hoskins and J. Simske, unpubl.). Because let-23 and let-60 display lethal null phenotypes, we used the partial loss-of-function let-23 allele, (n1045), and the dominant-negative let-60 allele, $(n 1531 d n)$. Animals that are homozygous for let-23(n1045) or heterozygous for let$60(n 1531 \mathrm{dn})$ are viable but vulvaless, indicating that the anchor cell-signaling pathway is nonfunctional or severely defective. The temperature-sensitive allele let-23(n1045ts) displays a 50\% lethal, $49 \%$ vulvaless, and $1 \%$ wild-type phenotype at $15^{\circ} \mathrm{C}$ (Ferguson and Horvitz 1985). The dominant-negative allele let$60(n 1531 d n)$ displays recessive lethal and dominant vulvaless phenotypes (Beitel et al. 1990). Hence, these data show that lin-31 mutations allow the expression of $1^{\circ}$ and $2^{\circ}$ cell fates in animals carrying let-23 and let-60 vulvaless mutations, but they do not prove that lin-31 mutations would allow expression of these fates in animals completely lacking let-23 and let-60 gene activity. Nevertheless, the let- 23 and let- 60 vulvaless mutations used above cause a severe defect in vulval induction, indicating that expression of $1^{\circ}$ and $2^{\circ}$ cell fates in lin-31 mutants is independent, or nearly independent, of let-23 or let-60 gene activity.

bPercent animals that are multivulva, excluding animals that die due to the let-23 or let-60(dn) mutations.

$c|+|$ Strains in which most animals have a vulva and can lay eggs; $|-|$ strains in which almost all animals are vulvaless.

${ }^{\mathrm{d}}$ let-60(n1531dn)/dpy-20 unc-30.

'lin-31(n1053); let-60(n1531dn)/dpy-20 unc-30. 
fates by P3.p, P4.p, or P8.p. Furthermore, all of these doubly mutant strains produce many animals $(>50 \%$ ) that can lay eggs, indicating that a functional vulva has been formed as a result of the expression of $1^{\circ}$ and $2^{\circ}$ cell lineages by P5.p, P6.p, or P7.p. The pattern of Pn.p cell divisions for each of these double mutants is similar to the pattern of deregulated cell fates exhibited by lin-31 mutants (data not shown). Figure 4 shows examples of
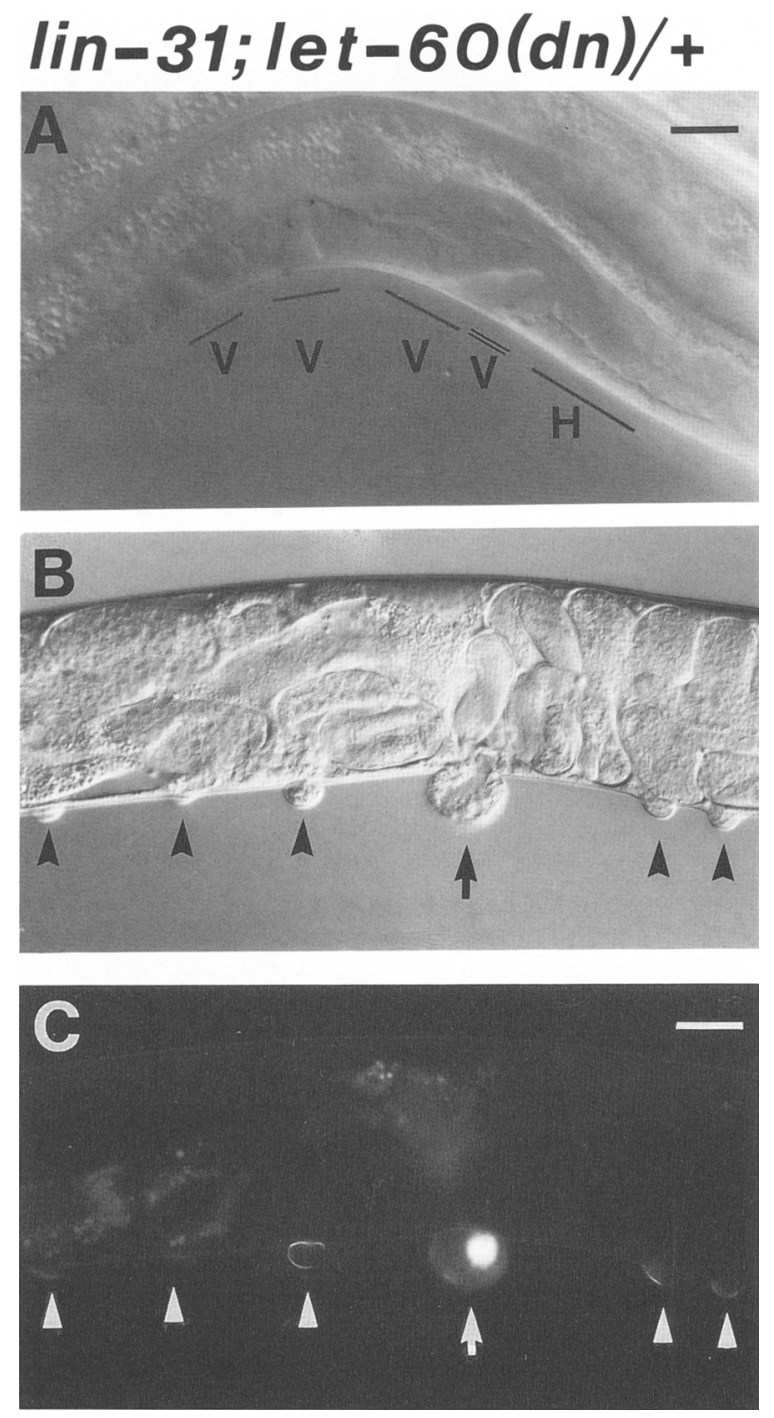

Figure 4. The lin-31 deregulated phenotype is epistatic to the let-60 ras vulvaless phenotype. (A) lin-31(n1053); let$60(n 1531 d n) /+$ animal viewed by Nomarski optics during the L4 larval stage. P3.p and P4.p have each expressed either the $1^{\circ}$ or $2^{\circ}$ lineage, generating extra vulval cells undergoing cellular invagination. P6.p descendants are double-underlined. Bar, 10 $\mu \mathrm{m} .(B)$ lin-31(n1053); let-60(n1531dn)/ + adult animal viewed by Nomarski optics, showing extra vulva cells that form ventral protrusions (arrowheads). Vulva is marked by an arrow. $(C)$ Same animal as in $B$, stained with FITC-Con A and viewed by fluorescence microscopy. The extra vulval cells (arrowheads) and vulva (arrow) stain with FITC-Con A. Bar, for B and C, 25 $\mu \mathrm{m}$. lin-31/lin-31; let-60(dominant negative) $/+$ animals in which vulval precursor cells have expressed $1^{\circ}$ or $2^{\circ}$ cell fates. The observation that the lin-31 mutant phenotype is epistatic to the let-23 receptor and let-60 ras mutant phenotypes indicates that the $\operatorname{lin}-31$ gene product acts after these steps in the anchor cell signaling pathway.

lin-31 encodes a member of the HNF-3/ fork head family of transcription factors

We cloned the lin-31 gene to understand how it controls vulval cell fates at the molecular level. Previously, we had identified a transposon-induced restriction-fragment length polymorphism (gaP13) that is located within 0.1 map units of lin-31 on the genetic map, suggesting that this polymorphism is physically located within $30 \mathrm{~kb}$ of the gene (S. Kim and H. R. Horvitz, unpubl.). We cloned a HindIII fragment containing this polymorphism and used the C. elegans physical map to identify a large set of overlapping cosmid and YAC clones that span gaP13 (S. Kim and A. Coulson, unpubl.). In particular, the YAC clone $\mathrm{Y} 14 \mathrm{H} 12$ contains $\sim 100 \mathrm{~kb}$ of flanking sequence on either side of the gaP13 polymorphic site.

The YAC clone Y14H12 rescued the lin-31 mutant phenotype in germ-line transformation experiments and therefore contains the entire lin-31 gene (Fig. 5B; Materials and methods). To rapidly map the location of the lin-31 gene within the $190-\mathrm{kb}$ insert in $\mathrm{Y} 14 \mathrm{H} 12$, we used a novel technique involving recombination in yeast to generate a nested set of deletion derivatives of $\mathrm{Y} 14 \mathrm{H} 12$ (see Fig. 5A; Materials and methods) and then introduced each derivative into the germ line of lin-31 mutants to test for lin-31 rescuing activity. These YAC derivatives localized the rescuing activity to a region within the cosmid F39D1. Subsequent rescue experiments with the cosmid F39D1 and with plasmid subclones derived from that cosmid defined a $9-\mathrm{kb}$ region that contains full lin31 rescuing activity (Fig. 5B).

We have identified a single gene within the $9 \mathrm{~kb}$ of DNA defining the lin-31 region (Fig. 5C), and the following results provide compelling evidence that this gene is lin-31. First, using genomic probes that completely span the lin-31 region in Northern blot hybridization experiments, we have detected only one RNA transcript (1.5 kb) (Fig. 6; Materials and methods). Second, this transcript maps to the region of DNA that is necessary and sufficient for lin-31 rescuing activity; DNA that can express the entire transcript (pLM203) has rescuing activity, whereas clones that lack either the $3^{\prime}$ end of the transcript (pLM206) or $5^{\prime}$ regulatory sequences (pLM205) cannot completely rescue the lin-31 mutant phenotype. Third, Southern blot hybridization experiments show that three lin-31 alleles (n1291, n1282, and ga37) are insertions in the $5^{\prime}$ end of the $1.5-\mathrm{kb}$ transcription unit and that one allele (n376) is a 600-bp deletion near the $3^{\prime}$ end (Fig. 5C; Materials and methods). Finally, Northern blot hybridization experiments show that the n1291, n1282, and $n 376$ mutations alter the size and amount of the $1.5 \mathrm{~kb}$ RNA, and the ga37 insertion results in the elim- 
A

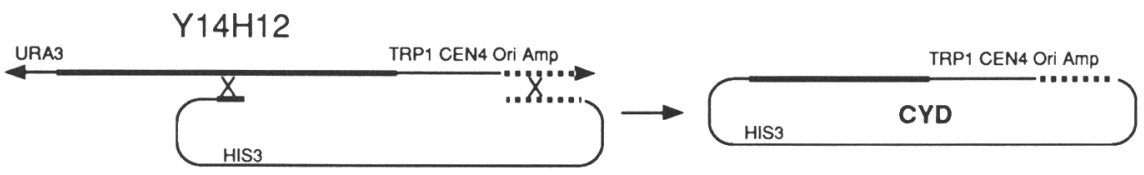

B

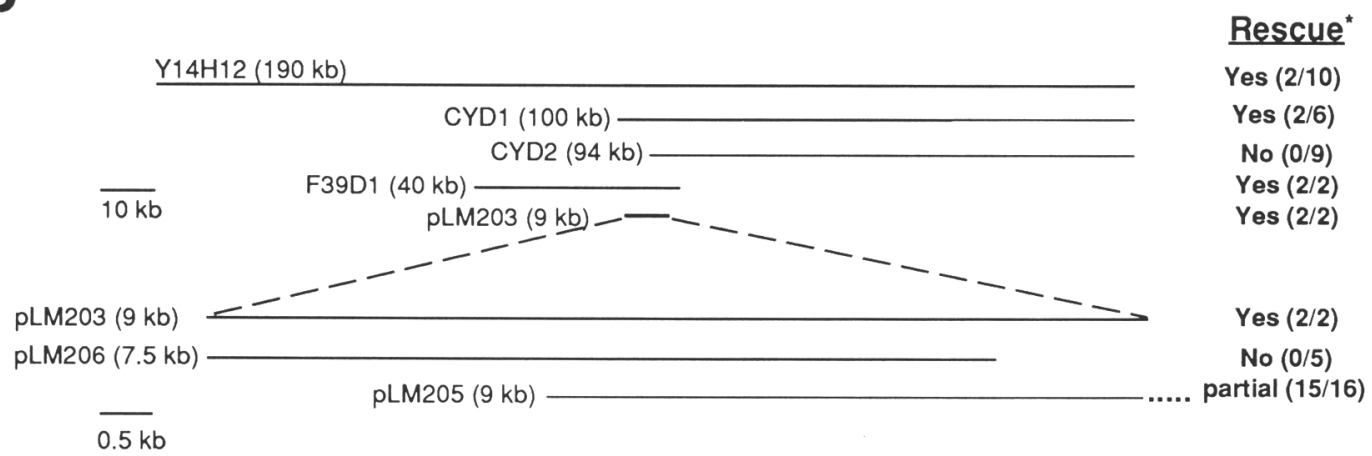

C

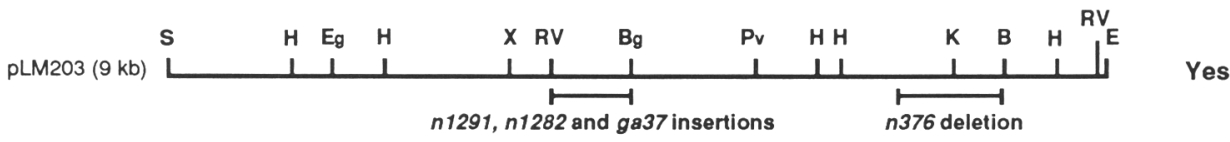

$\overline{0.5 \mathrm{~kb}}$

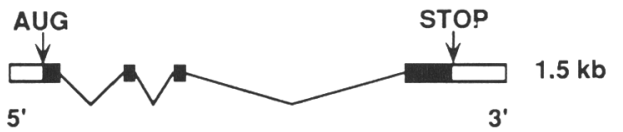

D

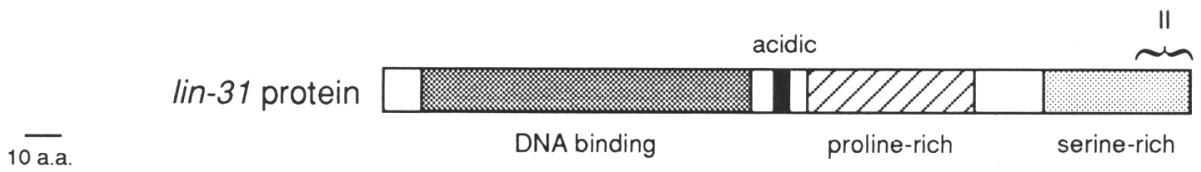

Figure 5. lin-31 region. (A) Strategy for creating circular YAC derivatives. Recombination in yeast was used to generate circular YAC derivatives (CYDs) from a linear YAC (Y14H12) by a gap-repair mechanism (see Materials and methods). Yeast and plasmid selectable markers are shown. The thick lines represent nematode DNA, the thin lines represent yeast vector DNA, the dotted lines represent plasmid DNA, and the arrowheads represent yeast telomeres. $(B)$ Identification of the lin-31 region by transformation rescue. Each clone has been tested for its ability to complement the mutant phenotype of lin-31 (Materials and methods). CYD1 and CYD2 are circular derivatives of Y14H12. F39D1 is a cosmid. pLM203, pLM205, and pLM206 are plasmids derived from F39D1. The lines represent the size and relative spacing of the nematode DNAs in each clone, as determined by DNA fingerprint analysis (A. Coulson and J. Sulston, pers. comm.), Southern blot hybridization, and restriction map analysis. Numbers in parentheses indicate the number of transformed lines showing lin-31 complementation out of the total number of transformed lines. ( ${ }^{*}$ ) Plasmid and cosmid DNA was injected at high concentration and showed high rates of cotransformation with rol-6(su1006d). YAC and CYD DNA was injected at low concentration and exhibited variable rates of cotransformation with rol-6(su1006d). For pLM205, 14 of the 15 rescued lines exhibited only partial complementation (25-83\% of the Rol animals were non-Lin) (see Materials and methods). pLM205 extends 3.5 $\mathrm{kb}$ to the right of the $E c O R I$ site. We attribute the partial rescue displayed by pLM205 to the absence of $5^{\prime}$ regulatory sequences in that clone. $(C)$ Structure of the lin-31 gene. Restriction map of the 9-kb clone pLM203. As determined by Southern blot analysis, bars below the restriction map indicate the boundaries of insertion and deletion mutations (see Materials and methods). The splicing pattern of the lin-31 transcript was derived by a comparison of genomic and cDNA sequences. Boxes represent exons. Solid boxes indicate the lin-31 open reading frame. (S) SacI; (H) HindIII; (Eg) EagI; (X) XhoI; (RV) EcoRV; (Bg) BglII; (Pv) PvuII; (K) KpnI, (B) BamHI; (E) EcoRI. (D) The lin-31 protein. A schematic representation of the predicted lin-31 protein is presented, showing the HNF-3/fork head DNA-binding domain, the acidic region, the proline-rich region, the serine-rich region, and the homologous region II (indicated by the bracket above the serine-rich region).

ination of the 1.5-kb transcript (Fig. 6). Thus, the gene expressing the $1.5-\mathrm{kb}$ transcript is lin-31.
We used anchored PCR experiments to isolate cDNA clones from this region (Materials and methods), and a 


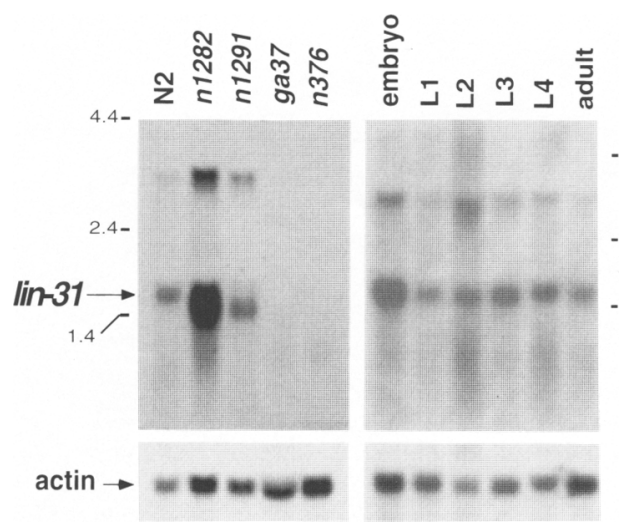

Figure 6. Northern blot analysis of lin-31 expression. Each lane contains $\sim 20 \mu \mathrm{g}$ of poly(A) ${ }^{+}$RNA, hybridized to a lin-31 cDNA probe (top). The left autoradiograph shows RNA from wild-type and lin-31 mutants in the L 3 larval stage. The band at $1.5 \mathrm{~kb}$ represents the 1 in $-31 \mathrm{RNA}$. This band is altered in size and intensity in RNA from $n 1282$ and n1291 mutants, significantly reduced in RNA from $n 376$ mutants, and absent in RNA from ga 37 mutants. Longer exposures show no $1.5-\mathrm{kb}$ transcript in the ga37 lane and many smaller transcripts in the $n 376$ lane, presumably because the $n 376$ deletion results in an unstable transcript. The band at $\sim 3.5 \mathrm{~kb}$ is not seen reproducibly and is likely attributable to gel migration artifacts caused by contaminating rRNA. The same band is also seen when an actin clone is used as a probe (data not shown). The right autoradiograph shows RNA from wild-type animals at different developmental stages. Adults are young adults with no embryos. To normalize for the amount of RNA in each lane, both filters were hybridized to an actin probe (Krause and Hirsh 1984; Kim and Horvitz 1990 ) following the removal of lin-31 probe (bottom).

comparison of the length of the composite cDNA (1497 bp) to the size of the mRNA detected by Northern blot hybridization experiments $(1.5 \mathrm{~kb})$ indicates that these cDNA clones represent most, if not all, of the lin-31 transcript. Northern blot hybridization experiments show that the 1.5-kb lin-31 transcript is expressed at all stages of development (Fig. 6).

The complete nucleotide sequence of the lin-31 composite cDNA is shown in Figure 7 . The open reading frame present in this cDNA is 714 bp long and encodes a predicted protein of 237 amino acids. We compared the predicted lin-31 protein sequence to sequences contained in the SWISSPROT data base using the program FASTA (Pearson and Lipman 1988) and found that the lin-31 protein is a member of the HNF-3/fork head family (Weigel et al. 1989; Lai et al. 1991). HNF-3 was originally identified on the basis of its ability to bind the promoters of two genes, transthyretin and $\alpha 1$-antitrypsin, preferentially expressed in the liver (Costa et al. 1989). Subsequent studies showed that HNF-3 could act as a transcriptional activator and defined a 110-aminoacid domain that was sufficient for binding to DNA. The lin-31 protein displays a striking similarity to the DNAbinding domains of the HNF-3 and fork head, ranging from $67 \%$ to $70 \%$ identity within the 96 -amino-acid consensus region (Fig. 8A). A second region of similarity with members of the HNF-3/fork head family is found at the carboxyl terminus of the predicted lin-31 protein sequence (Fig. 8B).

Although the similarity of the predicted lin-31 protein to the HNF-3/fork head family is restricted to the two domains described above, several regions outside of these domains are worth noting (Figs. 5D and 7). There are six consecutive aspartic acid residues on the carboxyl side of the DNA-binding region, and a 48-amino-acid region rich in prolines $(33 \%)$ is located near the carboxyl terminus of the predicted lin-31 protein. Acidic and proline-rich regions have been shown previously to act as activation domains in other transcription factors $(\mathrm{Ma}$ and Ptashne 1987; Mitchell and Tjian 1989). Finally, a 45 -amino-acid region rich in serines $(40 \%)$ is located at the carboxyl terminus of the predicted lin-31 protein,

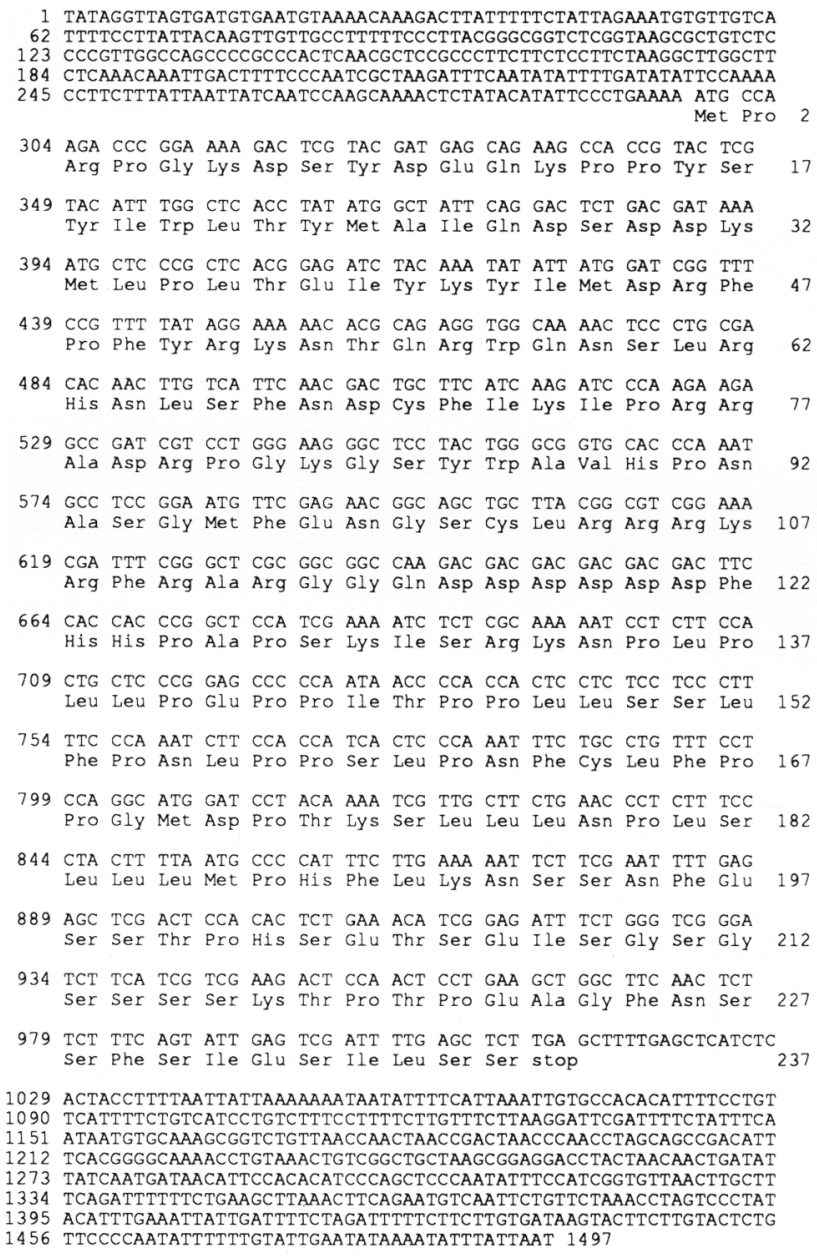

Figure 7. lin-31 sequence. Sequence of lin-31 composite cDNA and predicted amino acid sequence. Nucleotides are numbered on the left, and amino acids on the right. The conserved region within the HNF-3/fork head DNA-binding domain is located between amino acids 13 and 109 . The six consecutive aspartic acid residues are at positions $116-121$. The proline-rich region is located between amino acids 125 and 172 . The serine-rich region is between amino acids 193 and 237 . Homology region II is located between amino acids 225 and 237 . 
IIN-31 KPPYSYIWFTYMAIQD SDDEMLPFIEIYKY TMDRFPFYRKNTERWQNSLR FKH KPPYSYISLITMAIONNPT RMLTLSEIYQEIMDLFPFYRQNQQRWQNSTR HNF-3 $\alpha$ KPPYSYISIITMAIQQAP SKMITISEIYQWIMDIFPYYRQNQQRWQNSIR HNF-3 3 KPPYSYISLITMAIQQSPNKMITLSEIYQWIMDIFP FYRQNQQRWQNSIR HNF-3Y KPPYSYISLITMAIOOAP GKMLTLSEIYQWIMDLFPYYRENQQRWONSIR

\begin{tabular}{|c|c|}
\hline IIN-31 & 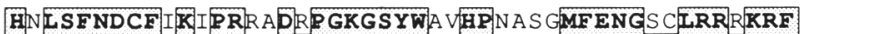 \\
\hline & HSLSFNDCFVKI PR DKPGKGSETLHPDSGNMFENGCYLRR \\
\hline & FVKV̈ARSPDKPGKGSYWTLHPDSGNMFENGCYLF \\
\hline & CFIKVPRAPDKP GKGSEWTLHPD SGNMFENGCYLRRQKRF-70 \\
\hline & RSPDKPGKGSYWALHPSSGNMFENGCYLRRQKRF- 69 \\
\hline
\end{tabular}

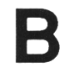

\begin{tabular}{|c|c|c|}
\hline LIN-31 & FNSSFSIGSIISS & \\
\hline FKH & S SHP F SINRILPTESK & -318 \\
\hline $\mathrm{HNE}-3 \alpha$ & FNHPESINNLMS\$\$EQ & -548 \\
\hline $\mathrm{HNE}-3 \beta$ & FNHP F INNLMSS-EO & -548 \\
\hline HNE $-3 \gamma$ & FNHPESINNLMS - EO & 468 \\
\hline
\end{tabular}

Figure 8. Comparison of conserved regions in lin-31, HNF-3, and fork head proteins. (A) Comparison of the 96-amino-acid conserved region in the HNF-3/fork head DNA-binding domain. Amino acids identical in three or more of the five proteins shown are boxed and shaded. The percent identity with lin-31 is shown. FKH refers to the Drosophila fork head protein (Weigel et al. 1989) and HNF-3 $\alpha$, $\beta$, and $\gamma$ refer to rat hepatocyte nuclear factors $3 \alpha, 3 \beta$, and $3 \gamma$, respectively (Lai et al. 1990, 1991). Additional members of the HNF-3/fork head family include proteins from yeast (Oliver et al. 1992), Xenopus (Dirksen and Jamrich 1992; Knöchel et al. 1992; Ruiz i Altaba and Jessell 1992), Drosophila (Grossniklaus et al. 1992; Häcker et al. 1992), rats (Tao and Lai 1992), and humans (Li et al. 1991; 1992). (B) Comparison of the 16-amino-acid region II. The percent identity with lin-31 is shown. The predicted lin-31 protein sequence lacks a third region (region III) that is sometimes found in HNF-3/fork head members as a poorly conserved domain of 16 amino acids.

providing many potential sites for protein phosphorylation. The striking similarity between lin-31 and the HNF-3/fork head family, and the observation that the lin-31 protein is likely to contain transcriptional activation domains suggest that lin-31 acts as a transcriptional regulator in the determination of vulval cell fates.

\section{Discussion}

One of the consequences of cell-cell signaling is the redirection of transcriptional activity in the nucleus in response to signaling events at the cell surface. Previous genetic studies of $C$. elegans vulval development have identified signaling genes involved in the production, reception, or transduction of an inductive signal, but these studies have not identified a nuclear target for these signaling genes. Here, we have presented the first characterization of a gene that may act as a transcriptional regulator in the anchor cell-signaling pathway. The lin31 gene encodes a protein with striking homology to DNA-binding transcription factors and may thus act to control vulval cell fates by directly regulating vulval gene expression. Cell ablation and genetic epistasis experiments indicate that $l i n-31$ acts downstream of five other vulval signaling genes, suggesting a model in which the lin-31 gene product in the nucleus either serves as a target or interacts with a target for signal transduction molecules at the plasma membrane. The function of the lin-31 regulatory gene is to allow vulval precursor cells to make the correct choice of cell fates in response to extracellular signals. In mutants lacking lin31 activity, these cells cannot properly choose which fate to express and, as a result, they express one of their three potential fates in a deregulated fashion.

\section{lin-31 acts late in vulval signaling}

We have presented two lines of evidence indicating that lin-31 acts at a late step in the anchor cell-signaling pathway. First, lin- 31 mutants can express $1^{\circ}$ and $2^{\circ}$ cell fates even if early steps in the anchor cell-signaling pathway are defective. Early steps in the signaling pathway were blocked either by use of a laser to ablate the precursor to the anchor cell or by use of mutations that eliminate or reduce gene activity in any one of five genes that are required in the anchor cell signaling pathway. One of these five genes, let-60, encodes the homolog of the ras signal transduction molecule and is predicted to act early in the signaling pathway because ras homologs are localized to the plasma membrane (Kim et al. 1990). Each of the remaining four genes (lin-2, lin-7, lin-10, and let23) are also likely to act early in the anchor cell-signaling pathway because genetic studies suggest that each acts upstream of let-60 [lin-2, lin-7, and lin-10 (S. Kim, J. Simske, R. Hoskins, unpubl.; S. Clark, pers. comm.); let-23 (Han et al. 1990)]. If lin-31 were to act at an early step in the anchor cell-signaling pathway upstream of let- 60 ras, one would expect that the expression of induced cell fates caused by the lin-31 mutation would depend on the wild-type activity of downstream genes, including let-60 ras. Thus, the observation that a lin-31 mutation causes these induced fates to be expressed independently of the activity of any of the five early acting genes that were tested, or the presence of the anchor cell itself, implies that lin-31 acts at a late step in the anchor cell-signaling pathway. The lin-1 gene also acts at a late step in anchor cell signaling, downstream of let-60 (Han et al. 1990); however, analysis of the lin-31; lin-1 double mutant has not yet allowed us to establish the genetic order between these two genes (D. Eisenmann, unpubl.). 
A second line of evidence supporting a late function for 1 in-31 comes from our molecular studies. The high degree of sequence similarity between lin-31 and HNF-3 suggests that lin-31 acts as a transcriptional regulator in vulval development. Our molecular and genetic data suggest a simple model, in which lin-31 completes a signaling circuit in vulval development involving a signal (lin-3), a receptor (let-23), transducer (let-60), and a transcription factor (lin-31) (Fig. 9). Although this is the simplest model that accounts for our molecular and genetic data regarding lin-31, other possible explanations remain because the site of action has not been established for many of the above genes, including lin-31.

\section{Control of vulval cell fates by lin-31}

In wild-type animals, the proximity of the anchor cell controls the fates of the vulval precursor cells. The cell next to the anchor cell (P6.p) always expresses the $1^{\circ}$ cell fate, cells at an intermediate distance from the anchor cell (P5.p and P7.p) always express the $2^{\circ}$ cell fate, and cells far from the anchor cell (P3.p, P4.p, and P8.p) always express the $3^{\circ}$ cell fate. The $1 i n-31$ gene has an interesting mutant phenotype that is unique among vulval determination genes; in lin-31 mutants, each of the six vulval precursor cells can adopt any one of the three possible cell fates $\left(1^{\circ}, 2^{\circ}\right.$, or $\left.3^{\circ}\right)$. Thus, this deregulated defect in lin-31 mutants represents an indecision about which fate to express rather than an inability to execute a particular fate, indicating a regulatory role for lin-31.

Explanations of the role lin-31 may play in the regulation of vulval cell fates must account for two aspects of the lin-31 mutant phenotype. First, lin-31 mutations can affect the fates of all six Pn.p cells, indicating that wild-

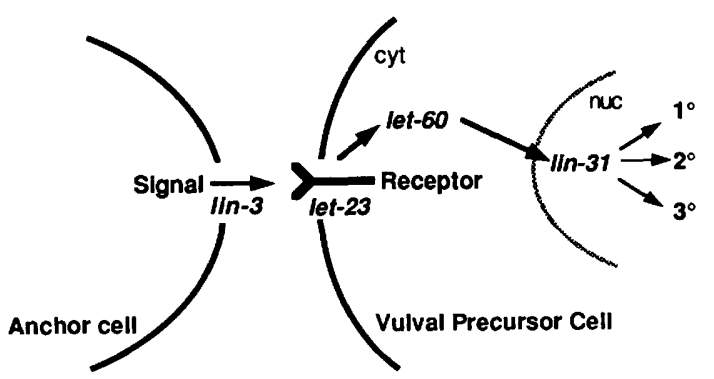

Figure 9. A model for the anchor cell-signaling pathway. This model indicates the genetic order for several of the vulval determination genes, including an inducing signal from the anchor cell (lin-3), a receptor (the let-23 tyrosine kinase), a ras homolog (let-60), and a transcription factor (lin-31) (see text for details). This model does not imply that these genes interact directly, as several steps in the pathway may require intermediate genes that have not yet been identified. There are several ways in which lin-31 may interact with the upstream signaling genes. lin-31 activity may be regulated by the anchor cell-signaling pathway or lin-31 may interact with other gene products that are themselves regulated by the anchor cell-signaling pathway. lin-31 is equally likely to be an activator or a repressor of vulval cell fates. type lin-31 activity is required for the proper specification of all three vulval cell fates. Second, lin-31 mutations do not cause Pn.p cells to reproducibly express an intermediate or indeterminate cell fate, but rather they result in the expression of discrete fates $\left(1^{\circ}, 2^{\circ}\right.$ or $\left.3^{\circ}\right)$ such that the same Pn.p cell may adopt different fates in different animals. These issues are discussed in the following two sections.

\section{Alternative lin-31 activities}

The observation that all six Pn.p cells require wild-type lin-31 activity for the proper choice of cell fate implies that lin-31 plays different functional roles in the determination of three alternative vulval cell fates. How can the same gene have different functions in different cells? One possibility is that the 1 in -31 protein itself could exist in alternative forms (e.g., by alternative protein phosphorylation) and that each of these forms might specify a different fate. The expression of alternative forms of the lin-31 protein would likely be regulated by the anchor cell-signaling pathway; let-60 ras could activate downstream effector molecules, and these effector molecules would themselves regulate the expression of different forms of the lin-31 protein, leading to the initiation of different cell fates.

A second possibility is that the lin-31 protein does not change in response to signaling but, instead, interacts with different factors in different cells. These factors would require the lin-31 gene product for their activity, and the resulting distinct interactions would lead to the expression of alternative cell fates. By this model, these interacting factors would be the nuclear targets that change in response to activation of the anchor cell-signaling pathway.

Both models presented above predict that lin-31 activity is required by each of the Pn.p cells to choose the right fate, implying that the absence of lin-31 activity represents a state that does not occur during wild-type development. Thus, unlike many other regulatory genes, lin-31 does not function as a developmental switch that specifies one fate when it is active (on) and another when it is inactive (off). Instead, lin-31 is a gene that has alternative functions because it is required for the proper specification of all three vulval cell fates.

\section{Deregulated expression of vulval cell fates}

Because lin-31 is involved in specifying all three vulval cell fates, one might expect that vulval precursor cells would consistently express an intermediate cell fate in mutants lacking lin-31 gene activity. Instead, vulval precursor cells in lin-31 mutants express discrete vulval cell fates $\left(1^{\circ}, 2^{\circ}\right.$, or $\left.3^{\circ}\right)$, but in a deregulated fashion. The same cell in different lin-31 mutant animals can express any of the three potential vulval cell fates. Because lin-31 mutants retain the ability to express all three cell fates, it seems unlikely that lin-31 directly regulates terminal differentiation genes. A more likely possibility is that lin-31 controls the activity of regulatory genes for each of 
the three cell fates, and these regulatory genes directly control the expression of the terminal differentiation genes. In the absence of lin-31 activity, each of these regulatory genes might be expressed at basal levels. There are several ways in which the simultaneous expression of these regulatory genes at basal levels could be developmentally unstable. For example, each of these genes could be capable of auto-activation, such that a small fluctuation in the basal level of activity for one of these genes would raise its activity above a critical level for selfactivation. This would result in greater levels of its own expression and eventually give rise to the initiation of a discrete cell fate. Thus, in the absence of lin-31 activity, cells would express fates in a deregulated fashion on the basis of the stochastic self-activation of a regulatory gene.

The above model implies a positive regulatory role for lin-31. An equally likely possibility is that lin-31 is a negative regulator of the $1^{\circ}, 2^{\circ}$, and $3^{\circ}$ vulval precursor cell fates. In this model, the repression by lin-31 would be inactivated in a position-dependent manner by the anchor cell-signaling pathway.

There are many examples in which the determination of developmental fates can appear to be stochastic, similar to the deregulated specification of cell fates observed in lin-31 mutants. Two such examples are the life cycle of bacteriophage $\lambda$ and the determination of sexual fate in certain Drosophila mutants. In each case, small fluctuations in the amount of an auto-activated regulatory molecule can cause a cell in an initially indeterminate state to express a discrete developmental fate. Lambda repressor, which controls the choice between the lytic or lysogenic fates of phage $\lambda$, can activate its own expression (Ptashne et al. 1980). Consequently, cells that express low levels of $\lambda$ repressor are developmentally unstable, because small fluctuations in the initial levels of $\lambda$ repressor expression can raise its concentration above a critical threshold for autoactivation, leading to the full expression of repressor and the establishment of the lysogenic fate. In Drosophila melanogaster, sex lethal protein promotes the female mode of sex determination and can activate its own expression by regulating the splicing of sex lethal RNA (Cline 1984, 1988; Bell et al. 1991). Sex determination is invariant in the wild type because sex lethal is properly regulated. In mutants defective in the regulation of sex lethal, however, individual cells express either a completely male or a completely female fate in a deregulated fashion because the positive autoregulatory activity of sex lethal can amplify small fluctuations in initial levels of sex lethal expression into all-or-none differences in final sex lethal concentration. In this regard, the variable sexual phenotype that results from defective regulation of sex lethal expression resembles the deregulated cell fate phenotype of lin-31 mutants.

\section{Signaling pathways}

The vulval signaling pathway is remarkably similar to the signaling pathways that specify the fate of the R7 photoreceptor cell in the Drosophila eye and that mediate the proliferation response to platelet-derived growth factor in mammalian fibroblasts. In each of these pathways, the cellular response to an extracellular signal is initiated by the activation of a receptor tyrosine kinase, and a ras homolog is used to transduce the signal received by the receptor (Greenwald and Rubin 1992; Treisman and Ammerer 1992). The finding that lin-31 may act as a transcription factor in the vulval signaling pathway suggests that lin-31 may play a similar role to the sina (Carthew and Rubin 1990) and glass (Moses et al. 1989) genes in Drosophila and to the serum response factor in mammals (Norman et al. 1988). Each of these genes encodes a transcription factor that may mediate the response to the activation of a receptor tyrosine kinase-signaling pathway. None of these transcription factors, however, share homology with lin-31 or each other (Norman et al. 1988; Moses et al. 1989; Carthew and Rubin 1990). Thus, although these genes appear to function at equivalent points in these signaling pathways, they each use different protein motifs to carry out their functions.

\section{Materials and methods}

\section{General methods and strains}

Standard techniques were used for maintenance and handling of C. elegans strains (Brenner 1974). Animals were grown at $20^{\circ} \mathrm{C}$ unless otherwise indicated. The animals described as wild-type were C. elegans, variety Bristol, strain N2 (Brenner 1974). The genetic markers used are listed below. Unless otherwise noted, all C. elegans mutations are described in Wood (1988).

LGI: lin-10(n1390) (Kim and Horvitz 1990), unc-29(e1072). LGII: lin-31(e1750, n301, n376, n428, n429, n435, n762, n1048, n1049, n1050, n1053) (Ferguson and Horvitz 1985), lin31(n1282, n1290, n1291) (Kim and Horvitz 1990), lin-31(ga9) (gift from G. Garriga), lin-31(ga10) (gift from M. Herman), lin31 (ga37), mutator allele derived from TR679 (Collins et al. 1987), unc-85(e1414), bli-2(e768), let-23(n1045), lin-7(e1413), nDf3. LGIV: let-60(n1531dn) (Beitel et al. 1990), dpy-20(e1282), unc-30(e191), rol-6(su1006d). LGX: dpy-3(e27), lin-2(e1309), unc-3(e151).

Yeast strains DBY1812 and AB1380 were provided by David Botstein and Alan Coulson, respectively.

\section{Genetic techniques}

To determine the phenotype of lin-31(n1053)/Df animals, N2 males were crossed with $n D f 3 / u n c-85$ hermaphrodites, and single cross progeny males from that mating were crossed with hermaphrodites of genotype lin-31(n1053) bli-2; dpy-3 unc-3. Approximately one-half of the cross progeny from one-half of the matings were Muv, non-Bli, non-Dpy, non-Unc and assumed to be of genotype lin-31(n1053) bli-2/nDf3; dpy-3 unc$3 /++$. Thus, $n 1053 / D f$ and n1053/n1053 hermaphrodites display identical multivulva phenotypes. Similar experiments were performed previously for another lin-31 allele, n301 (Greenwald and Horvitz 1980).

Standard genetic techniques were used to construct all double mutant strains. Because lin-31; vul double mutants do not display a vulvaless phenotype, we confirmed that these strains were homozygous at the vul locus (vul represents lin-2, lin-7, lin-10, or let-23). lin-31; vul mutants were crossed with wild- 
type males, and 10 cross progeny were picked to individual plates. Each of the cross progeny was observed to segregate vulvaless hermaphrodites that continued to segregate only vulvaless animals, indicating that the parental double mutant was homozygous for the vulvaless mutation.

\section{Cell lineage analysis}

Pn.p cell lineages were analyzed as described in Sulston and Horvitz (1977), using the criteria for the assignment of $1^{\circ}, 2^{\circ}$, and $3^{\circ}$ cell fates described in Sternberg and Horvitz (1986).

\section{FITC-Con A staining}

Animals were stained with FITC-Con A essentially as described in Link et al. (1988). Animals were washed in M9 buffer, stained for $1 \mathrm{hr}$ in $200 \mu \mathrm{g} / \mathrm{ml}$ of FITC-Con A (Sigma), washed in M9 buffer containing $10 \mathrm{~mm}$ sodium azide, and resuspended in M9 buffer containing $10 \mathrm{~mm}$ sodium azide and $10 \%$ Citifluor (Citifluor Ltd, London, UK). Animals were mounted on agar pads containing $10 \mathrm{~mm}$ sodium azide and visualized using epifluorescence microscopy.

\section{Laser ablation}

We ablated the nuclei of $\mathrm{Zl}$ and $\mathrm{Z} 4$ in newly hatched $\mathrm{L} 1$ larvae by the method of Sulston and White (1980) using equipment described in Avery and Horvitz (1987). Because Z1 and Z4 form the entire somatic gonad, including the anchor cell, this ablation completely eliminates the expression of the anchor cell inductive signal at the L3 stage.

\section{Yeast recombination}

To test whether the YAC clone $\mathrm{Y} 14 \mathrm{H} 12$ could rescue the lin-31 phenotype in microinjection experiments, we separated the YAC DNA from yeast chromosomal DNA by pulsed field gel electrophoresis (Schwartz and Cantor 1984; Chu et al. 1986), using a $1 \%$ agarose gel with a switch time of between 15 and 24 sec. The YAC DNA was cut out of the gel and isolated by electroelution, phenol extraction, and ethanol precipitation.

We generated a nested set of deletion derivatives of the YAC clone Y14H12 using gap repair in yeast (Orr-Weaver et al. 1983; Pavan et al. 1990). We used standard yeast techniques to construct the strain SKY2 (Y14H12, MATa, ura3-52, leu2-3,112, his $3 \Delta 200$, lys2-1, can1-100, trp1), by crossing the $\mathrm{Y} 14 \mathrm{H} 12$ clone contained in strain AB1380 (MATa, ura3, trp1, ade1, can1-100, lys2-1, his5) (Coulson et al. 1986) into the yeast strain DBY1812

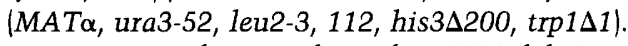

To generate the nested set of $\mathrm{Y} 14 \mathrm{H} 12$ deletion derivatives, we constructed a library of XbaI-EcoRI DNA fragments from F39D1 (a cosmid contained within Y14H12) in the HIS3 yeast vector pRB328 (Ma et al. 1987). The library was digested with EcoRI, yielding linear DNA molecules with one end homologous to the YAC vector and the other end homologous to nematode sequences contained in the YAC insert. The library of linear DNA was used to transform yeast strain SKY2, and HIS ${ }^{+}$ colonies were selected. Most $\mathrm{HIS}^{+}$colonies were circular plasmids containing nematode, autonomously replicating sequences (ARS) and centromere (CEN) sequences derived from the YAC. These circular YAC derivatives (CYDs) are likely the result of a gap repair, in which the linear DNA had recombined with $Y A C$ vector sequence and with nematode insert sequence. Because the $X b a I-E c o R I$ DNA fragments were randomly inserted in both orientations relative to the YAC clone, approximately half of the linearized library could yield circular YAC derivatives. The sizes of the inserts were determined by analyzing total yeast DNA from the CYD-containing strains in Southern blot hybridization experiments using F39Dl as a probe. The 16 clones analyzed fell into six size categories; CYD2 and CYD1 are representative clones of the fourth and fifth largest size classes, respectively. We used an alkaline lysis procedure (Devenish and Newlon 1982) to prepare CYD1 and CYD2 DNA for microinjection.

\section{Germ-line transformation experiments}

Germ-line transformation was performed by the method of Fire (1986), as modified by Mello (Mello et al. 1991), using DNA from the lin-31 region $(10-100 \mu \mathrm{g} / \mathrm{ml})$ and the marker pRF4 (100 $\mu \mathrm{g} / \mathrm{ml}$ ) (Kramer et al. 1990), which carries an allele of the gene rol-6(su1006d) that confers a dominant roller phenotype. For clones that completely rescue the lin-31 phenotype (e.g., pLM203), $>90 \%$ of the animals are non-Lin in most, or all, of the transgenic lines. The plasmid pLM205 can only partially rescue the lin-31 mutant phenotype; 14 of 16 lines containing transgenic pLM205 DNA exhibit non-Lin animals at a frequency of $25-83 \%$, only 1 of 16 pLM205 transformant line displays $>90 \%$ non-Lin animals, and 1 of 16 lines exhibited no non-Lin animals.

\section{Manipulation of DNA and RNA}

Standard techniques were used for all molecular biology experiments (Sambrook et al. 1989). DNA probes were labeled by random priming (Feinberg and Vogelstein 1983).

The plasmids shown in Figure 5 contain the following DNA inserts in the vector Bluescript SK + (Stratagene): pLM203 contains a 9-kb SpeI-EcoRI fragment, pLM205 contains a 9-kb Xhol-SpeI fragment, and pLM206 contains a 7.5-kb SpeI-KpnI fragment.

The lin-31 allele-specific polymorphisms shown in Figure 5 were mapped by Southern blot hybridization experiments (data not shown). The $n 376$ allele is a 600 -bp deletion that resides within the 1.6-kb HindIII-BamHI fragment and removes the KpnI site. The $n 1282, n 1291$, and ga37 alleles are 1.7-kb insertions in the $1.0-\mathrm{kb}$ EcoRV-BglII fragment. In addition, there is another insertion associated with the $n 1282$ allele several kilobases upstream of the lin-31 gene. No allele-specific polymorphisms were found in the following lin-31 alleles: e1750, ga9, ga10, n301, n428, n435, n1048, n1049, n1050, and n1053.

Populations of developmentally staged nematodes were obtained by growing large-scale liquid cultures (Sulston and Brenner 1974) of synchronized animals (Emmons et al. 1979; Nelson et al. 1982) for varying lengths of time. Animals at the L1 larval stage were obtained by hatching eggs overnight in M9 medium, feeding the starved, synchronized larvae for $2-3 \mathrm{hr}$, and collecting by low-speed centrifugation. Subsequent stages were collected when $>80 \%$ of the animals in the culture exhibited stage-specific markers. For the L2 stage, the marker was the appearance of the postdeirid, a characteristic group of neurons (Sulston and Horvitz 1977). The Pn.p cell divisions marked the L3 stage, the formation of the vulva marked the L4, and young adults were collected after the L 4 molt and before embryos were visible.

To isolate RNA, 2.5 volumes of buffer $(2 \%$ SDS, $50 \mathrm{mM}$ Tris$\mathrm{HCl}$, and $10 \mathrm{mM}$ EDTA/ and 2.5 volumes of phenol/chloroform (1:1) were added to frozen pellets of worms $(1-4 \mathrm{ml})$, and the mixture was sonicated until it thawed. The lysate was extracted three to five times with phenol/chloroform. Poly $\mid A)^{+}$RNA was isolated by a single round of selection on an oligo(dT)-cellulose column (Sambrook et al. 1989). 
Hybridization buffer for Northern blot hybridization experiments consisted of $10 \times$ Denhardt's solution, $5 \times$ SSPE, $0.5 \%$ SDS, and $100 \mu \mathrm{g} / \mathrm{ml}$ of denatured salmon sperm DNA. Filters were washed in $0.4 \times \mathrm{SSPE}, 0.5 \% \mathrm{SDS}$, at $65^{\circ} \mathrm{C}$. To strip filters of probe before rehybridization, filters were washed in $6 \times$ SSPE, $50 \%$ formamide, at $65^{\circ} \mathrm{C}$ for $1 \mathrm{hr}$. RNA markers (Bethesda Research Laboratories) were visualized by staining with methylene blue (Sambrook et al. 1989).

Northern blot hybridization experiments were performed using probes from genomic DNA to detect RNAs from the lin-31 region. Both the $1.2-\mathrm{kb} B g I I-P v u I I$ probe and a probe made from a clone spanning pLM203 detect only one transcript of $1.5 \mathrm{~kb}$. No RNA bands were observed using a probe for the region 5 ' to lin-31 (4-kb SpeI-EcoRV fragment) or a probe within the large intron (1-kb HindIII-KpnI fragment).

Genomic DNA was sequenced on both strands between the EagI and EcoRI sites on clone pLM203. This sequence was used to design primers for the isolation of cDNA clones. cDNA clones were obtained using lin-31-specific primers to amplify cDNAs in anchored PCR experiments (Frohman et al. 1988). For cDNA clones representing the $3^{\prime}$ end of $l i n-31$, cDNA was first synthesized from $25 \mu \mathrm{g}$ of total RNA from wild-type hermaphrodites at the $\mathrm{L} 3$ larval stage using a linkered oligo(dT) primer (5'-GACTCGAGTCGACATCGAT $\left.17^{\prime}-3^{\prime}\right)$ and AMV reverse transcriptase. lin-31 cDNAs were amplified in a PCR experiment 12 min at $50^{\circ} \mathrm{C}, 3 \mathrm{~min}$ at $72^{\circ} \mathrm{C}, 1 \mathrm{~min}$ at $95^{\circ} \mathrm{C}$ for 30 cycles), using a lin-31-specific primer 15'-CGCTCACGGAGATCTACAAATA-3' at position 401-422 in the lin-31 gene and a nonspecific primer matching the first oligo(dT) primer $\left(5^{\prime}\right.$-GACTCGAGTCGACATCG-3'). XhoI sites are underlined, and BgIII sites are double-underlined. The primer ends of the PCR products were cut with BglII and XhoI, and the PCR product was cloned into the Bluescript $\mathrm{SK}+$ vector (Stratagene), yielding the cDNA clone pLM269. cDNA clones representing the $5^{\prime}$ end of lin-31 were obtained in a similar fashion, except that cDNA was first synthesized using a lin-31-specific primer $\left(5^{\prime}\right.$-CCTATAAAACGGAAACCGATCC-3') at position 450-429, followed by the addition of oligo(dA) tails using terminal transferase and dATP. This experiment produced one predominant band of $\sim 0.5 \mathrm{~kb}$. lin-31 cDNAs were then amplified by use of a lin-31specific primer (5'-TATTTGTAGATCTCCGTGAGCG-3') at position 422-401 and the same modified, nonspecific oligo(dT) primer used above $\left(5^{\prime}\right.$-GACTCGAGTCGACATCGAT $\left.17_{17}-3^{\prime}\right)$ in a polymerase chain reaction experiment using the amplification conditions described above. The PCR products were cloned into the vector Bluescript SK + after the primer ends had been cut with Sall (dotted underline) and BglII, yielding multiple cDNA clones, of which pLM270 is an example. The anchored PCR procedures described above identify the major $5^{\prime}$ and $3^{\prime}$ ends of the lin-31 transcript (Fig. 5C).

Unidirectional nested deletions for sequencing were generated using exonuclease III (Yanisch-Perron et al. 1985). Singlestranded templates were sequenced either by dideoxy chain termination (Sanger et al. 1977) using Sequenase DNA polymerase 2.0 or by an $\mathrm{ABI}$ automated sequencing system. DNA sequences were manipulated and analyzed using DNA Strider 1.1 (Marck 1988) and IntelliGenetics GeneWorks 1.0.

\section{Note added in proof}

The nucleotide sequence data reported in this paper have been submitted to GenBank and assigned the accession number L11148.

\section{Acknowledgments}

The lin-31 alleles ga 9 and ga10 were kindly provided by G.
Garriga and M. Herman, respectively. pRB328 and pRF4 were generously provided by $\mathrm{D}$. Botstein and J. Kramer, respectively. We thank H.R. Horvitz for strains and the use of the laser for the ablation studies. We also thank D. Garza, B. Dunne, and D. Preuss for expert yeast advice, A. Coulson and J. Sulston for aid in mapping gaP13 and for providing YAC and cosmid clones, S. Clark for communicating results before publication, and J. Bellenson for expert sequencing help. We also thank the C. elegans Genetic Center for providing strains. We are especially grateful to A. Villeneuve, D. Eisenmann, D. Preuss, and P. Schatz for comments on the manuscript, and the entire Kim laboratory for stimulating discussions and comments. This work was supported by grants from the Lucille P. Markey Charitable Trust, the Searle Scholars Program/The Chicago Community Trust, and the National Institutes of Health. L.M.M. was supported by an American Cancer Society postdoctoral fellowship and B.A.M. was supported by a National Science Foundation graduate fellowship. S.K.K. is a Lucille P. Markey scholar and a Searle scholar.

The publication costs of this article were defrayed in part by payment of page charges. This article must therefore be hereby marked "advertisement" in accordance with 18 USC section 1734 solely to indicate this fact.

\section{References}

Aroian, R.V., M. Koga, J.E. Mendel, Y. Ohshima, and P.W. Sternberg. 1990. The let-23 gene necessary for Caenorhabditis elegans vulval induction encodes a tyrosine kinase of the EGF receptor subfamily. Nature 348: 693-699.

Avery, L. and H.R. Horvitz. 1987. A cell that dies during wildtype C. elegans development can function as a neuron in a ced-3 mutant. Cell 51: 1071-1078.

Beitel, G.J., S.G. Clark, and H.R. Horvitz. 1990. Caenorhabditis elegans ras gene let-60 acts as a switch in the pathway of vulval induction. Nature 348: 503-509.

Bell, L., J. Horabin, P. Schedl, and T. Cline. 1991. Positive autoregulation of sex-lethal by alternative splicing maintains the female determined state in Drosophila. Cell 65: 229-239.

Brenner, S. 1974. The genetics of Caenorhabditis elegans. Genetics 77: 71-94.

Carthew, R.W. and G.M. Rubin. 1990. seven in absentia, a gene required for specification of $\mathrm{R} 7$ cell fate in the Drosophila eye. Cell 63: 561-577.

Chu, G., D. Vollrath, and R.W. Davis. 1986. Separation of large DNA molecules by contour-clamped homogeneous electric field. Science 234: 1582-1585.

Clark, S.G., M.J. Stern, and H.R. Horvitz. 1992. C. elegans cell-signalling gene sem-5 encodes a protein with $\mathrm{SH} 2$ and $\mathrm{SH} 3$ domains. Nature 356: 340-344.

Cline, T. 1988. Evidence that sisterless- $a$ and sisterless- $b$ are two of several discrete "numerator elements" of the X/A sex determination signal in Drosophila that switch $S x l$ between two alternative stable expression states. Genetics 119: 829-862.

Cline, T.W. 1984. Autoregulation functioning of a Drosophila gene product that establishes and maintains the sexually determined state. Genetics 107: 231-277.

Collins, I., B. Saari, and P. Anderson. 1987. Activation of a transposable element in the germ line but not the soma of $C$. elegans. Nature 328: 726-728.

Costa, R.H., D.R. Grayson, and J.J. Darnell. 1989. Multiple hepatocyte-enriched nuclear factors function in the regulation of transthyretin and alpha 1-antitrypsin genes. Mol. Cell. Biol. 9: 1415-1425.

Coulson, A., J. Sulston, S. Brenner and J. Karn. 1986. Toward 
a physical map of the genome of the nematode C. elegans. Proc. Natl. Acad. Sci. 83: 7821-7825.

Devenish, R.J. and C.S. Newlon. 1982. Isolation and characterization of yeast ring chromosome III by a method applicable to other circular DNAs. Gene 18: $277-288$.

Dirksen, M.L. and M. Jamrich. 1992. A novel, activin-inducible, blastopore lip-specific gene of Xenopus laevis contains a fork head DNA-binding domain. Genes \& Dev. 6: 599-608.

Emmons, S.W., M.R. Klass, and D. Hirsh. 1979. Analysis of the constancy of DNA sequences during development and evolution of the nematode Caenorhabditis elegans. Proc. Natl. Acad. Sci. 76: 1333-1337.

Feinberg, A.P. and B. Vogelstein. 1983. A technique for radiolabeling DNA restriction endonuclease fragments to high specific activity. Anal. Biochem. 132: 6-13.

Ferguson, E.L. and H.R. Horvitz. 1985. Identification and characterization of 22 genes that affect the vulval cell lineages of the nematode Caenorhabditis elegans. Genetics 110: 17-72.

Fire, A. 1986. Integrative transformation of Caenorhabditis elegans. EMBO I. 5: 2673-2681.

Frohman, M.A., M.K. Dush, and G.R. Martin. 1988. Rapid production of full-length cDNAs from rare transcripts: Amplification using a single gene-specific oligonucleotide primer. Proc. Natl. Acad. Sci. 85: 8998-9002.

Greenwald, I.S. and H.R. Horvitz. 1980. unc-93(e1500): A behavioral mutant of Caenorhabditis elegans that defines a gene with a wild-type null phenotype. Genetics 96: 147-164.

Greenwald, I. and G.M. Rubin. 1992. Making a difference: The role of cell-cell interactions in establishing separate identities for equivalent cells. Cell 68: 271-281.

Grossniklaus, U., R.K. Pearson, and W.J. Gehring. 1992. The Drosophila sloppy paired locus encodes two proteins involved in segmentation that show homology to mammalian transcription factors. Genes \& Dev. 6: 1030-1051.

Häcker, U., U. Grossniklaus, W.J. Gehring, and H. Jäckle. 1992. Developmentally regulated Drosophila gene family encoding the fork head domain. Proc. Natl. Acad. Sci. 89: 8754 8758.

Han, M. and P.W. Sternberg. 1990. let-60, a gene that specifies cell fates during $C$. elegans vulval induction, encodes a ras protein. Cell 63: 921-931.

Han, M., R.V. Aroian, and P.W. Sternberg. 1990. The let- 60 locus controls the switch between vulval and nonvulval cell fates in Caenorhabditis elegans. Genetics 126: 899-913.

Herman, R.K. and E.M. Hedgecock. 1990. Limitation of the size of the vulval primordium of Caenorhabditis elegans by lin-15 expression in surrounding hypodermis. Nature 348: 169171.

Hill, R.J. and P.W. Stemberg. 1992. The gene lin-3 encodes an inductive signal for vulval development in C. elegans. Nature 358: $470-476$.

Horvitz, H.R. and P.W. Stemberg. 1991. Multiple intercellular signalling systems control the development of the Caenorhabditis elegans vulva. Nature 351: 535-541.

Kim, R., J. Rine, and S.H. Kim. 1990. Prenylation of mammalian Ras protein in Xenopus oocytes. Mol. Cell. Biol. 10: 59455949.

Kim, S.K. and H.R. Horvitz. 1990. The Caenorhabditis elegans gene lin-10 is broadly expressed while required specifically for the determination of vulval cell fates. Genes \& Dev. 4: 357371 .

Kimble, J. 1981. Alterations in cell lineage following laser ablation of cells in the somatic gonad of Caenorhabditis elegans. Dev. Biol. 87: 286-300.

Knöchel, S., J. Lef, J. Clement, B. Klocke, S. Hille, M. Köster, and W. Knöchel. 1992. Activin A induced expression of a fork head related gene in posterior chordamesoderm (notochord) of Xenopus laevis embryos. Mech. Dev. 38: 157-165.

Kramer, J.M., R.P. French, E.C. Park, and J.J. Johnson. 1990. The Caenorhabditis elegans rol-6 gene, which interacts with the sqt-1 collagen gene to determine organismal morphology, encodes a collagen. Mol. Cell. Biol. 10: 2081-2089.

Krause, M. and D. Hirsh. 1984. Actin gene expression in Caenorhabditis elegans. In Molecular biology of the cytoskeleton (ed. G.G. Borisy, D.W. Cleveland, and D.B. Murphy), pp. 244258. Cold Spring Harbor Laboratory, Cold Spring Harbor, New York.

Lai, E., V.R. Prezioso, E. Smith, O. Litvin, R.H. Costa, and J.E. Darnell Jr. 1990. HNF-3, a hepatocyte-enriched transcription factor of novel structure is regulated transcriptionally. Genes \& Dev. 4: 1427-1436.

Lai, E., V.R. Prezioso, W.F. Tao, W.S. Chen, and J.J. Darnell. 1991. Hepatocyte nuclear factor 3 alpha belongs to a gene family in mammals that is homologous to the Drosophila homeotic gene fork head. Genes \& Dev. 5: 416-427.

Lambie, E.J. and J. Kimble. 1991. Genetic control of cell interactions in nematode development. Annu. Rev. Genet. 25: $411-436$.

Li, C., C.F. Lai, D.S. Sigman, and R.B. Gaynor. 1991. Cloning of a cellular factor, interleukin binding factor, that binds to NFAT-like motifs in the human immunodeficiency virus long terminal repeat. Proc. Natl. Acad. Sci. 88: 7739-7743.

Li, C., A.J. Lusis, R. Sparkes, S.M. Tran, and R. Gaynor. 1992. Characterization and chromosomal mapping of the gene encoding the cellular DNA binding protein HTLF. Genomics 13: 658664.

Link, C.D., C.W. Ehrenfels, and W.B. Wood. 1988. Mutant expression of male copulatory bursa surface markers in Caenorhabditis elegans. Development 103: 485-495.

Ma, H., S. Kunes, P.J. Schatz, and D. Botstein. 1987. Plasmid construction by homologous recombination in yeast. Gene 58: $201-216$.

Ma, J. and M. Ptashne. 1987. A new class of yeast transcriptional activators. Cell 51: 113-119.

Marck, C. 1988. DNA Strider: A C program for DNA and protein sequences analysis. Nucleic Acids Res. 16: 1829-1836.

Mello, C.C., J.M. Kramer, D. Stinchcomb, and V. Ambros. 1991. Efficient gene transfer in C. elegans: Extrachromosomal maintenance and integration of transforming sequences. $E M B O$ J. 10: 3959-3970.

Mitchell, P. and R. Tiian. 1989. Transcriptional regulation in mammalian cells by sequence-specific DNA binding proteins. Science 245: 371-378.

Moses, K., M.C. Ellis, and G.M. Rubin. 1989. The glass gene encodes a zinc-finger protein required by Drosophila photoreceptor cells. Nature 340: 531-536.

Nelson, G.A., T.M. Roberts, and S. Ward. 1982. Caenorhabditis elegans spermatozoan locomotion: Amoeboid movement with almost no actin. J. Cell Biol. 92: 121-131.

Norman, C., M. Runswick, R. Pollock, and R. Treisman. 1988. Isolation and properties of CDNA clones encoding SRF, a transcription factor that binds to the $c$-fos serum response element. Cell 55: 989-1003.

Oliver, S.G., J.M. van der Aart, M.L. Agostoni-Carbone, M. Aigle, L. Alberghina, D. Alexandraki, G. Antoine, R. Anwar, J.P.G. Ballesta, P. Benit, et al. 1992. The complete DNA sequence of yeast chromosome III. Nature 357: 38-46.

Orr-Weaver, T.L., J.W. Szostak, and R.J. Rothstein. 1983. Genetic applications of yeast transformation with linear and gapped plasmids. Methods Enzymol. 101: 228-245.

Pavan, W.J., P. Hieter, and R.H. Reeves. 1990. Generation of deletion derivatives by targeted transformation of human-de- 
rived yeast artificial chromosomes. Proc. Natl. Acad. Sci. 87: 1300-1304.

Pearson, W.R. and D.J. Lipman. 1988. Improved tools for biological sequence comparison. Proc. Natl. Acad. Sci. 85: 24442448.

Ptashne, M., A. Jeffrey, A.D. Johnson, R. Maurer, B.J. Meyer, C.O. Pabo, T.M. Roberts, and R.T. Sauer. 1980. How the $\lambda$ repressor and Cro work. Cell 19: 1-11.

Ruiz i Altaba, A. and T.M. Jessell. 1992. Pintallavis, a gene expressed in the organizer and midline cells of frog embryos: Involvement in the development of the neural axis. Development 116: 81-93.

Sambrook, J., E.F. Fritsch, and T. Maniatis. 1989. Molecular cloning: A laboratory manual, 2nd ed. Cold Spring Harbor Laboratory Press, Cold Spring Harbor, New York.

Sanger, R., S. Nicklen, and A.R. Coulson. 1977. DNA sequencing with chain-terminating inhibitors. Proc. Natl. Acad. Sci. 74: 5463-5467.

Schwartz, D.C. and C.R. Cantor. 1984. Separation of yeast chromosome-sized DNAs by pulsed field gradient gel electrophoresis. Cell 37: 67-75.

Sternberg, P.W. 1988. Lateral inhibition during vulval induction in Caenorhabditis elegans. Nature 335: 551-554.

Sternberg, P.W. and H.R. Horvitz. 1986. Pattern formation during vulval development in C. elegans. Cell 44: 761-772.

Sulston, J.E. and S. Brenner. 1974. The DNA of Caenorhabditis elegans. Genetics 77: 95-104.

Sulston, J.E. and H.R. Horvitz. 1977. Post-embryonic cell lineages of the nematode, Caenorhabditis elegans. Dev. Biol. 56: $110-156$.

Sulston, J.E. and J.G. White. 1980. Regulation and cell autonomy during postembryonic development of Caenorhabditis elegans. Dev. Biol. 78: 577-597.

Tao, W. and E. Lai. 1992. Telencephalon-restricted expression of BF-1, a new member of the HNF-3/fork head gene family, in the developing rat brain. Neuron 8: 957-966.

Treisman, R. and G. Ammerer. 1992. The SRF and MCM1 transcription factors. Curr. Opin. Genet. Dev. 2: 221-226.

Weigel, D., G. Jürgens, F. Küttner, E. Seifert, and H. Jäckle. 1989. The homeotic gene fork head encodes a nuclear protein and is expressed in the terminal regions of the Drosophila embryo. Cell 57: 645-658.

Wood, W.B., ed. 1988. The Nematode Caenorhabditis elegans. Cold Spring Harbor Laboratory, Cold Spring Harbor, New York.

Yanisch-Perron, C., J. Vieira, and J. Messing. 1985. Improved M13 phage cloning vectors and host strains: Nucleotide sequences of the M13amp18 and pUC19 vectors. Gene 33: 103119. 


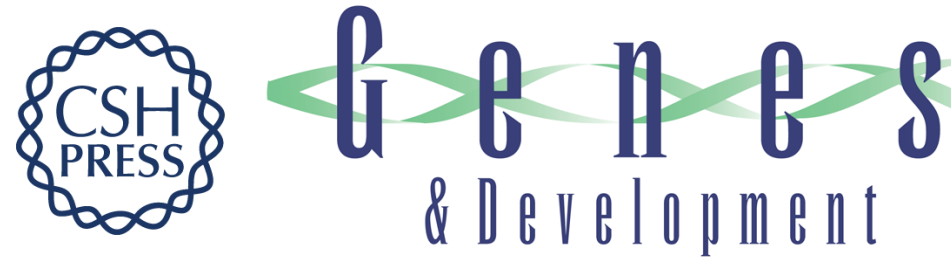

\section{lin-31, a Caenorhabditis elegans HNF-3/fork head transcription factor homolog, specifies three alternative cell fates in vulval development.}

L M Miller, M E Gallegos, B A Morisseau, et al.

Genes Dev. 1993, 7:

Access the most recent version at doi:10.1101/gad.7.6.933

References This article cites 65 articles, 28 of which can be accessed free at:

http://genesdev.cshlp.org/content/7/6/933.full.html\#ref-list-1

License

Email Alerting Receive free email alerts when new articles cite this article - sign up in the box at the top Service right corner of the article or click here.

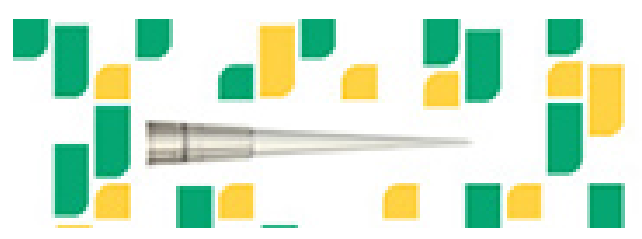

Focused on your science. 